

\title{
Screening for Nuclear Replacement Candidates in Patients With Lumbar Degenerative Disc Disease
}

Ioannis Pappou, Frank Cammisa, Jr., Elias Papadopoulos, Peter Frelinghuysen and Federico Girardi

Int J Spine Surg 2008, 2 (2) 114-119

doi: https://doi.org/10.1016/SASJ-2007-0116-RR

http://ijssurgery.com/content/2/2/114

This information is current as of April 26, 2023.

Email Alerts Receive free email-alerts when new articles cite this article. Sign up at:

http://ijssurgery.com/alerts

The International Journal of Spine Surgery

2397 Waterbury Circle, Suite 1,

Aurora, IL 60504, Phone: +1-630-375-1432 


\title{
Screening for Nuclear Replacement Candidates in Patients With Lumbar Degenerative Disc Disease
}

\author{
Ioannis Pappou, MD, ${ }^{a}$ Frank Cammisa Jr., MD, ${ }^{a}$ Elias Papadopoulos, MD, ${ }^{a}$ \\ Peter Frelinghuysen, $M D,{ }^{a}$ and Federico Girardi, $M D^{a}$
}

\begin{abstract}
Background

Nuclear replacement is an emerging surgical treatment for degenerative disc disease (DDD) and low back pain (LBP). While clinical experience is most extensive with the prosthetic disc nucleus PDN (Raymedica, Minneapolis, Minnesota), strict indications apply for the implantation of this device. The purpose of this study was to ascertain what percentage of patients treated surgically for degenerative disc disease with other surgical procedures would have been candidates for nuclear replacement implantation.
\end{abstract}

\section{Methods}

The charts and films of 85 consecutive patients with failed conservative management for LBP treated surgically with fusion, disc replacement, or annuloplasty were retrospectively reviewed. There were 53 patients with 1-level disease and 32 with 2 -level disease, accounting for 117 treated levels. Patients with the following radiographic contraindications to nuclear replacement were serially eliminated: (1) Schmorl's nodes and > 50\% collapse of the disc space, (2) irregular/convex endplates on the MRI, (3) complete tears and large annular defects (ie, both incomplete tears and complete tears were eliminated, but patients with local annular deficiency were deemed eligible for nuclear replacement), and (4) a BMI > 30.

Results

Fifty-nine levels $(50.4 \%)$ had no radiographic contraindications to treatment with a nuclear replacement device. Twelve levels in 10 patients with a BMI > 30 were excluded. Overall, 47 out of 117 levels $(40.2 \%)$ had no contraindications to a prosthetic nucleus device. The L5-S1 level was the most commonly treated level (55 out of $117,47 \%$ ), but only $25.5 \%$ had no radiographic contraindications, and overall only $21.8 \%$ of the levels were suitable for a nuclear replacement device. Upper lumbar levels (L3-4 and L4-5) had no radiographic contraindications in a higher percentage of cases (68.8\% and $72.7 \%$, respectively). The inclusion of the BMI criteria reduced these percentages to $50 \%$ and $59.1 \%$, respectively.

\section{Conclusions}

The surgeon has to assess endplate integrity, disc height, endplate shape, annular integrity, and BMI when offering nuclear replacement as treatment for patients with DDD.

Key Words: Prosthetic disc nucleus, degenerative disc disease, contraindications, indications, nuclear replacement. SAS Journal. Spring 2008;2:114-119. DOI: SASJ-2007-0116-RR

${ }^{a}$ Hospital for Special Surgery, New York, New York

Address correspondence to Federico P. Girardi, MD, Hospital for Special Surgery, 535 East 70th Street, New York, NY 10021 (email: girardif@hss.edu)

Frederico Girardi, MD, and Frank Cammisa, MD, are consultants with Raymedica.

Institutional Review Board approval was obtained from the Hospital for Special Surgery.

\section{INTRODUCTION}

Chronic low back pain (LBP) is widely recognized as a major cause of morbidity, health-related costs (conservative estimates: $\$ 50$ billion), and lost days at work in the US, mainly as a result of patients who become chronically debilitated. ${ }^{1}$ The options for treatment of this condition are conservative measures, ${ }^{2}$ minimally invasive methods (eg, intradiscal electrothermal therapy (IDET), radiofrequency nucleoplasty (RFN)), ${ }^{3}$ discectomy for nucleus pulposus herniations, ${ }^{4}$ and finally spinal fusion procedures (anterior and/or posterior). ${ }^{5-7}$
All current conservative and minimally invasive means fail to alter the course of degenerative disc disease (DDD) and address the pathology at the point of origin, namely the nucleus. ${ }^{8}$ The standard surgical treatment for LBP due to DDD is fusion, at the cost of ablating motion and possible degeneration at adjacent levels. ${ }^{9}$ Total disc replacement (TDR) is emerging as a motion-preserving option for selected patients ${ }^{10}$ and may cause less adjacent segment degeneration. ${ }^{11,12}$ However, both fusion and disc replacement are major operations, carrying the risk of infection, neurologic compromise, nerve/vessel injury, 
medical complications, and possible reoperation. ${ }^{7,9}$ Nuclear replacement is a less-invasive, motion-retaining treatment option for DDD at an early stage, theoretically preventing the associated degenerative cascade. ${ }^{13,14}$

A number of devices have been developed: Newcleus (Zimmer Spine, Warsaw, Indiana), Aquarelle (Stryker Howmedica Osteonics, Allendale, New Jersey), NeuDisc (Replication Medical, Cranbury, New Jersey), the Gelifex family of hydrogels (Synthes, West Chester, Pennsylvania), Aquacryl (Replication Medical), BioDisc (CryoLife, Kennesaw, Georgia), Dascor (Disc Dynamics, Eden Prairie, Minnesota), NuCore (Spine Wave, Shelton, Connecticut), Sinux ANR, (J\&J Depuy Acromed, Raynham, Massachusetts). ${ }^{14,15}$ Most clinical data are available for the PDN (Raymedica, Inc., Minneapolis, Minnesota), ${ }^{13,16,17}$ and therefore this study focuses on this device. The 4th generation PDN device is called Hydraflex; it is being implanted through an anterior retroperitoneal approach, and its theoretical advantages include a more anatomic contoured shape for a greater fit and fill, a softer core with a larger footprint to reduce the risk of subsidence, and faster hydration to allow faster stabilization. There are currently no published results of use of the newest device; all existing data is based on the first 3 PDN generations.

The major complication found with use of the previous PDN generational products is posterior device herniation causing compressive radiculopathy, which usually requires revision, consisting of removal of the device and placement of a smaller one, TDR, or a fusion. ${ }^{13,16,18-20}$ In the earliest and latest series this complication occurred in $8-12 \%$ of the patients, respectively. ${ }^{13,16,19,20}$ However, in the interim, extrusion rates were as high as $26 \%{ }^{16}$ and $38 \%,{ }^{19}$ because the risk factors for extrusion were not completely appreciated. A series with no herniation in 45 patients has been reported, ${ }^{18}$ albeit with only two-thirds of the patients returning for a 6-month follow-up and with use of the nuclear replacement device for a different indication (adjunct to microdiscectomy for disc herniation). In face of potential complications, not all patients with DDD would qualify for nuclear replacement. Careful patient selection is stressed by all authors as essential for surgical and clinical success. ${ }^{13,16,18-20}$

It is currently unknown what percentage of DDD cases would qualify for nuclear replacement using the device we evaluated. We looked for radiographic and clinical contraindications to treatment with the nuclear replacement device in a cohort of 85 patients with 117 surgically treated levels, and we highlighted the important factors and pitfalls in the decisionmaking. Briefly, suitable indications for the nuclear device include: intact endplates to prevent device subsidence into the vertebral body, disc collapse at the affected level less than $50 \%$, only small annular tears, no irregular or convex endplates, and $\mathrm{BMI}<30$. $^{13}$

\section{METHODS}

The institutional review board of the hospital approved the study. Charts and radiographs of 85 consecutively treated patients with lumbar degenerative disc disease and chief complaint of low back pain from 2001-2004 were retrospectively reviewed. The 85 patients received treatment at 117 levels in total. Patients with the generic diagnosis of DDD and additional spinal disease (facet arthrosis, spondylolisthesis, stenosis, scoliosis, tumor, or infection) were not included. All patients were recruited from the practice of the senior authors (F.P.C. and F.P.G.), and only patients with 1- and 2-level disease were selected for consistency. All patients had failed conservative treatment for a minimum of 6 months and were treated surgically for low back pain with IDET ( $\mathrm{n}=34)$, RFN ( $\mathrm{n}=3)$, posterior lumbar interbody fusion (PLIF; $n=12$ ) early in the series, and TDR $(n=36)$ later on. There were 85 patients with 117 treated levels; 53 patients had 1-level disease and 32 had 2-level disease. Mean age $( \pm$ SD) was $39.2( \pm 9)$, mean BMI was $26.3( \pm 4.8), 56.5 \%$ were males, and $43.5 \%$ were females. The treated levels were selected based on radiographic studies demonstrating disc degeneration and provocation discography (which included 1 control level). ${ }^{21}$ The absolute and relative distribution of treated levels is described in Table 1.

Table 1. Absolute and Relative Frequencies of Affected Levels

\begin{tabular}{lcc}
\hline Level & Frequency & $\%$ \\
\hline L2-3 & 2 & 1.7 \\
\hline L3-4 & 16 & 13.7 \\
\hline L4-5 & 44 & 37.6 \\
\hline L5-S1 & 55 & 47.0 \\
\hline Total & 117 &
\end{tabular}

Table 2. Classification of Disc Degeneration by Pfirrmann et al.

\begin{tabular}{|c|c|c|c|c|}
\hline Grade & $\begin{array}{l}\text { Structure } \\
\text { and Anulus }\end{array}$ & Distinction of Nucleus & $\begin{array}{c}\text { Signal Intensity } \\
\text { Intervertebral Disc }\end{array}$ & Height of \\
\hline 1 & $\begin{array}{l}\text { Homogeneous, } \\
\text { bright white }\end{array}$ & Clear & $\begin{array}{l}\text { Hyperintense, isotense to } \\
\text { cerebrospinal fluid }\end{array}$ & Normal \\
\hline II & $\begin{array}{l}\text { Inhomogeneous with or } \\
\text { without horizontal bands }\end{array}$ & Clear & $\begin{array}{l}\text { Hyperintense, isotense to } \\
\text { cerebrospinal fluid }\end{array}$ & Normal \\
\hline III & Inhomogeneous, gray & Unclear & Intermediate & Normal to slightly decreased \\
\hline IV & Inhomogeneous, gray to black & Lost & Intermediate to hypointense & Normal to moderately decreased \\
\hline V & Inhomogeneous, black & Lost & Hypointense & Collapsed disc space \\
\hline
\end{tabular}


Preoperative lumbar spine anteroposterior (AP) and lateral radiographs, MR scans, and CT-discograms were reviewed (I.P.P.). Specifically, the integrity of the endplate was assessed on plain AP and lateral radiographs of the lumbar spine by scrutinizing them for Schmorl's nodes. To identify patients with $>50 \%$ collapse at the affected level, the disc space height was measured at all 5 segments of the lumbar spine at the anterior, middle, and posterior portion on the lateral radiograph, as illustrated in Figure $1 .{ }^{22}$ The average disc height was calculated by dividing the sum of these values by 3. Furthermore, disc hydration was assessed on fluid-sensitive $\mathrm{T}^{2}$ MR sequences, according to Pfirrmann et al. (Table 2). ${ }^{23}$

Greater than $50 \%$ collapse at the affected level was defined as average disc height $<50 \%$ compared to the adjacent, asymptomatic level, if the adjacent level appeared well

\section{Figure 1.}

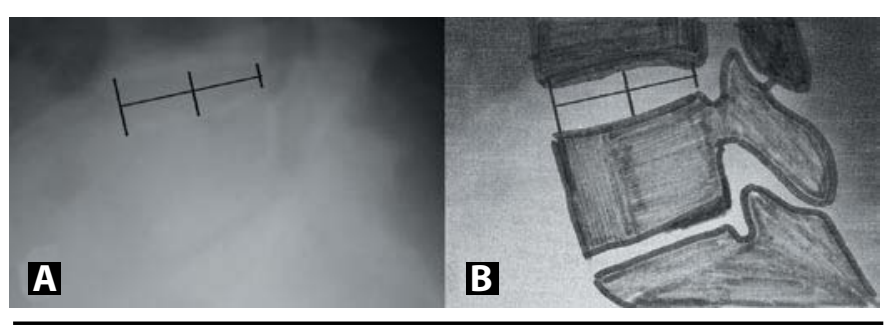

Disc height measurements at the anterior, mid- and posterior portion on lateral radiographs at the $L 4 / 5$ disc. A) radiograph B) drawing (Note that the L5-S1 segment is $>50 \%$ collapsed in comparison to the adjacent L4-5).

hydrated on the MRI (Grades 1-3), or the largest/best hydrated lumbar disc if the adjacent asymptomatic level appeared degenerated on the MRI (Grades 4 and 5) (Figure 2). The smallest device size is $5 \mathrm{~mm}$ in height, so it was initially suggested that the affected level should have a minimum disc height of $5 \mathrm{~mm}$ in the mid-portion of the disc. However, this may place larger compressive loads on the device and predispose to herniation.

\section{Figure 2.}

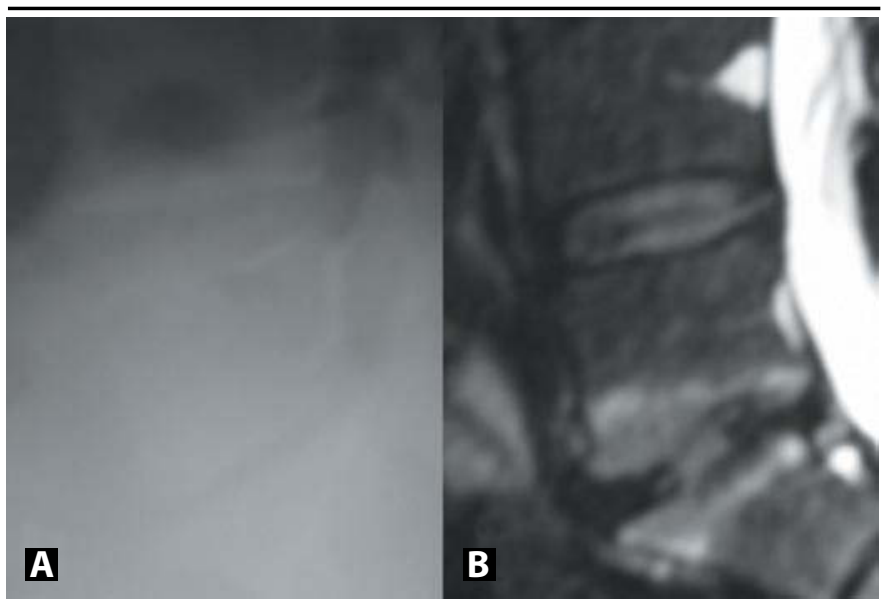

Appearance of a symptomatic L5-S1 segment with $>50 \%$ collapse on plain radiographs (A) and MRI (B). Adjacent segment is healthy on MRI (grade 2) and was therefore used as reference.

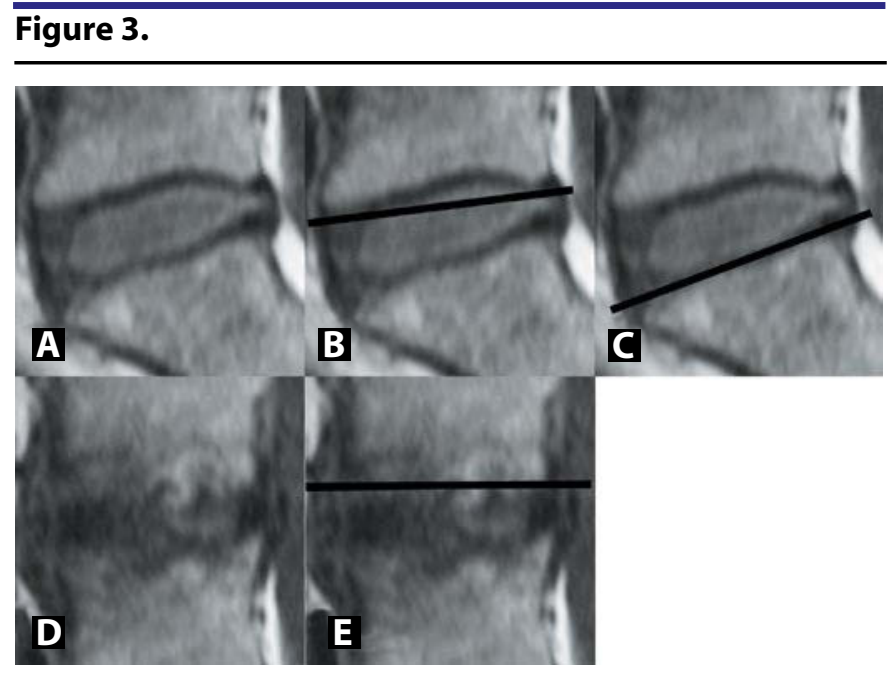

Therefore, the trials underway in the US use $<50 \%$ collapse as a radiographic criterion. We adhered to the latter guidelines.

The shape of the endplates at the affected levels was assessed on T1-weighted MR sequences and categorized as concave, flat, or convex. A radiolucent ruler was held across the endplate at the 3 mid-sagittal cuts. The shape of 2 of the 3 sections was used in cases of discrepancy (Figure 3). The endplate was designated concave if disc was visible between the ruler and the endplate (Figure 3B), flat if the endplate was seen to follow the ruler edge (Figure $3 \mathrm{C}$ ), and convex if excrescencies were seen above the edge (Figure 3E). On CT-discograms, the extent of annular tears and the degree of annular deficiency were graded according to the Dallas discogram description (Table 3, Figure 4). ${ }^{24}$ Finally, BMI was calculated for all patients from the height and weight at the initial office visit.

\section{Figure 4.}

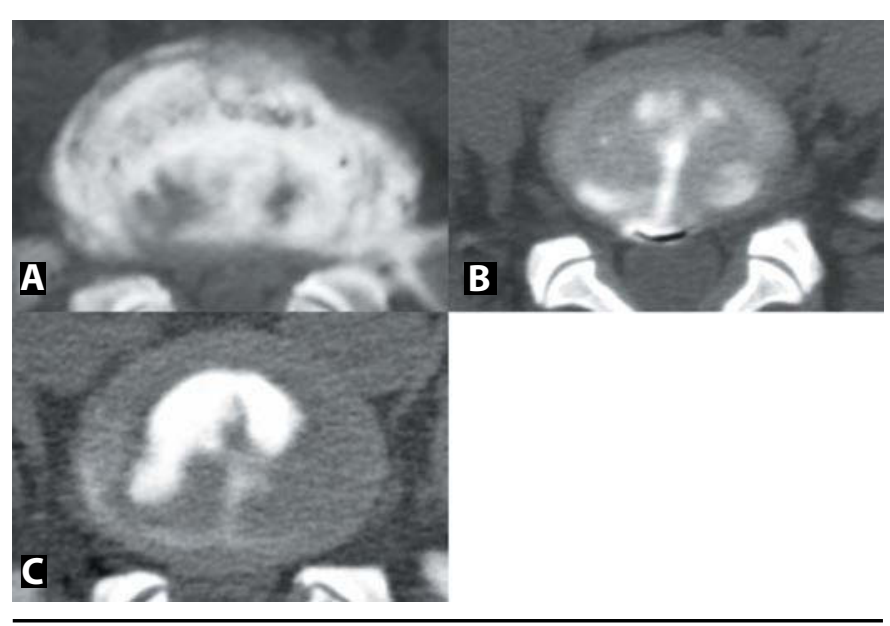

CT-discogram demonstrating (A) a severely degenerated disc/annulus, with a tear extending through all fibers and large annular deficiency $(>50 \%)$ - unsuitable for PDN implantation, (B) a complete but focal tear ( $<10 \%$ of annular periphery) -suitable for PDN implantation, and (C) an incomplete, focal tear-suitable for PDN implantation. 
Table 3.Dallas Classification of Disc Degeneration on CT-Discograms

\begin{tabular}{ll}
\hline $\begin{array}{c}\text { Degeneration } \\
\text { (Annulus) }\end{array}$ & $\begin{array}{c}\text { Annular disruption } \\
\text { (Contrast Extension) }\end{array}$ \\
\hline 0 - No change & 0 - None \\
1 - Local $(<10 \%)$ & 1 - Into inner annulus \\
2 - Partial $(<50 \%)$ & 2 - Into outer annulus \\
3 -Total $(>50 \%)$ & 3 -Beyond outer annulus \\
\hline
\end{tabular}

The order of films used for the serial examination was: plain radiographs, MRI, and finally CT-discograms, representing an ascending order of ease, cost, and invasiveness for film acquisition. After identifying the radiographic contraindications for nuclear disc replacement, a subset of patients that did not meet the criteria were serially eliminated. (1) Patients with Schmorl's nodes and $>50 \%$ collapse of the disc space were excluded. (2) Patients with irregular/ convex endplates on the MRI were eliminated. (3) Patients with large ( $>10 \%$ of the periphery) and complete annular tears (extending through all the fibers of the annulus) were excluded (Figure 4A). Patients with incomplete annular tears or complete annular tears, but local annular deficiency $(<10 \%$ of the periphery), were deemed eligible for prosthetic nucleus (Figures 4B, 4C). Patients with BMI $>30$ were excluded. Descriptive statistical analysis was performed using SPSS (SPSS Inc., Chicago, Illinois).
(50.4\%) with no radiographic contraindications to treatment with the nuclear replacement device.

The BMI was reviewed for the remaining patients, and patients with BMI $>30$ were also deemed poor candidates for nuclear replacement. Twelve levels in 10 patients were further eliminated (1 at L2-3, 3 at L3-4, 6 at L4-5, 2 at L5-S1). This changed the management for $10.3 \%$ of the levels. Six patients with 1-level disease (17.95\%) and 2 patients with 2level disease who could otherwise be treated with the nuclear replacement device at both levels were excluded because of their BMI. The remaining 2 levels were in patients with 2level disease and radiographic contraindications at the other level.

Overall, only 47 out of 117 levels (40.2\%) had no radiographic and clinical contraindications to nuclear replacement. The L5-S1 level was the most commonly treated level (56 levels, $47 \%$ ). However, only $25.5 \%$ of the L5-S1 levels had no radiographic contraindications. Overall, only $21.8 \%$ of the L5-S1 levels were amenable to treatment with nuclear replacement. Proximal lumbar levels (L3-4 and L4-5) had no radiographic contraindications in $68.8-72.7 \%$ of the cases (approximately 3 times more than L5-S1), but were all-around suitable forPDN in $50-59.1 \%$ of the cases in which BMI was used in the decision-making.

Table 4. Summary of the Levels Serially Eliminated Due to Rapidiographic and Clinincal Contraindications to Nuclear Replacement

\begin{tabular}{|c|c|c|c|c|c|c|c|c|c|c|}
\hline Level & Start & Schmorl & $\begin{array}{l}>50 \% \\
\text { Collapse }\end{array}$ & $\begin{array}{l}\text { Irregular } \\
\text { Endplates }\end{array}$ & $\begin{array}{l}\text { Insufficient } \\
\text { Ennulus }\end{array}$ & $\begin{array}{l}\text { No Radiographic } \\
\text { Contraindictions }\end{array}$ & $\%$ & $\begin{array}{c}\text { BMI> } \\
30\end{array}$ & $\begin{array}{c}\text { Overall Suitable } \\
\text { for Nuclear Replacement }\end{array}$ & $\%$ \\
\hline L2-3 & 2 & 0 & 0 & 0 & 0 & 2 & 100 & 1 & 1 & 50 \\
\hline L4-5 & 44 & 2 & 1 & 1 & 8 & 32 & 72.7 & 6 & 26 & 59.1 \\
\hline L5-S1 & 55 & 1 & 10 & 10 & 20 & 14 & 25.5 & 2 & 12 & 21.8 \\
\hline Totals & 117 & 4 & 11 & 11 & 32 & 59 & 50.4 & 12 & 47 & 40.2 \\
\hline
\end{tabular}

\section{RESULTS}

Poor candidates for the nuclear replacement device were identified on radiographic studies as follows: (1) Schmorl's nodes on radiographs were identified at 4 levels (1 at L3-4, 2 at L4-5, and 1 at L5-S1). (2) Greater than 50\% disc collapse was present at 11 levels of the remaining levels, and these were subsequently excluded (1 at L4-5 and 10 at L5-S1). Using $<5 \mathrm{~mm}$ as a contraindication to nuclear replacement, only 2 levels would be eliminated. However, applying 50\% collapse as a criterion for severe disc degeneration proved to be more restrictive, identifying all of the levels $<5 \mathrm{~mm}$ and an additional 9 levels. (3) Irregular/convex endplate shape was present in 11 of the remaining levels, and these were eliminated (1 at L4-5 and 10 at L5-S1). (4) Tears extending through all annular fibers (Grade 3) with partial or total annular deficiency (Grades 2 and 3) were identified in 32 of the remaining levels, which were excluded (4 at L3-4, 8 at L4-5, and 20 at L5-S1). We thus identified 59 out of 117 levels
Nuclear replacement was a treatment option for only $28.3 \%$ of the patients (15 of 53) with 1-level disease. Prosthetic nucleus was a treatment option at both levels for only $34.5 \%$ of the patients (11 of 32) with 2-level disease. However, an additional $18.8 \%$ (6 patients) could benefit from nuclear replacement at 1 level. Patients with 2-level disease were thus

Table 5. Overall Prevalence of Contraindications to Nuclear Replacement at Each Affected Level

\begin{tabular}{|c|c|c|c|c|c|c|}
\hline Level & Start & Schmorl & $\begin{array}{l}>50 \% \\
\text { Collapse }\end{array}$ & $\begin{array}{c}\text { Irregular } \\
\text { Endplates }\end{array}$ & $\begin{array}{c}\text { Insufficient } \\
\text { Annulus }\end{array}$ & $\begin{array}{c}\text { BMI> } \\
30\end{array}$ \\
\hline L2-3 & 2 & 0 & 0 & 0 & 0 & 1 \\
\hline L3-4 & 16 & 1 & 0 & 0 & 4 & 3 \\
\hline L4-5 & 44 & 2 & 1 & 2 & 13 & 9 \\
\hline L5-S1 & 55 & 1 & 10 & 15 & 34 & 8 \\
\hline Totals & 117 & 4 & 11 & 17 & 51 & 21 \\
\hline$\%$ & & 3.4 & 9.4 & 14.5 & 43.6 & 17.9 \\
\hline
\end{tabular}


more likely to be suitable for prosthetic nucleus implantation in at least 1 level than patients with 1-level disease in this series ( $P=.022$ using $\square^{2}$ test). The serial elimination of levels with radiographic and clinical contraindications to prosthetic nucleus implantation is summarized in Table 4.

The order followed for the identification of patients with contraindications to nuclear replacement was to exclude patients with radiographic contraindications, based on the ease, cost, and invasiveness of the radiographic studies and then to include the clinical data. However, a different algorithm can be used, and it would lead to the same result. For completeness of the data, we present the contraindications per level (a certain case may have more than 1 contraindication, which would not become apparent during the serial elimination) (Table 5).

It is apparent that endplate insufficiency, severe disc collapse, endplate shape irregularity, and annular insufficiency occurred most commonly at L5-S1. The L4-5 level had less radiographic and morphologic changes that would preclude the use of prosthetic nucleus than the L5-S1 level. However a high number of patients with L4-5 disease had a BMI > 30. A large percentage of cases (43.6\%) demonstrated annular insufficiency to a degree prohibitive for nucleus implantation, especially at the L5-S1 level (34 out of 55, 61.8\%). The CTdiscogram should thus be an integral part for the evaluation of patients considered for treatment with nuclear replacement. Also, since a contraindication was present in $17.9 \%$ (21 of 117) of all affected levels in patients because of BMI $>30$, the clinician should take the weight of the patient into serious consideration when offering various treatment options for patients with DDD.

\section{DISCUSSION}

The purpose of this study was to examine a group of patients with DDD and ascertain what percentage would be candidates for nuclear replacement with a specific prosthetic disc nucleus. In a previous study from our institution, contraindications to TDR were identified in $95 \%$ of patients with DDD, which included patients with various pathologies (stenosis, facet arthrosis, spondylolisthesis, scoliosis, etc). ${ }^{10}$ In this series, however, the goal was to selectively examine patients with DDD at 1 or 2 levels with chief complaint of pain, so other spinal pathology was excluded. Moreover, this study is a theoretical construct; the results of adhering to these guidelines for nucleus implantation cannot be reported. However, the results are useful to practicing spine surgeons, similar to the study by Huang et al. ${ }^{10}$

The prosthetic disc nucleus has been used mainly for patients with DDD at an early stage of the disease 16 and recently also for patients with nucleus pulposus herniation. ${ }^{20}$ Identified risk factors for device herniation are: large Schmorl's nodes, severe disc degeneration ( $<5 \mathrm{~mm}$ mid-portion or more recently $>50 \%$ collapse), irregular/convex remodeled endplates that do not fit to the implant shape, large annular tears, and as a clinical contraindication, BMI $>30$. Technical problems in the earlier series (larger annulotomies, use of smaller devices, failure to suture the 2 components together in the early generation paired design), inadequate nuclectomy and failure to adhere to the postoperative rehabilitation program were responsible for higher extrusion rates as well. ${ }^{13,16}$

Severe disc degeneration was described originally as $<5 \mathrm{~mm}$ height at the disc mid-portion, since the smaller device size is 5 $\mathrm{mm}$ in the dehydrated state. ${ }^{13,16,18-20}$ Stricter criteria apply now, and a disc with $<50 \%$ collapse compared to the adjacent level is the criterion currently used in clinical trials. Using these latter criteria and including the appearance of the adjacent asymptomatic disc on the MRI to assess disc degeneration, ${ }^{23}$ the levels $<5 \mathrm{~mm}$ were all correctly recognized and an additional $7.7 \%$ (9 out of 117 levels), which were not suitable for nuclear replacement, were identified in this patient series. This criterion was more restrictive and may prove critical in reducing the rate of device herniations in the trials underway.

The endplates of the affected level should be concave to accept the device. Disc plate sclerosis ${ }^{13,16}$ and aggravation of Modic changes ${ }^{20}$ are seen commonly, possibly as a result of altered stress distribution and likely have no correlation to clinical outcome. Severe osteoporosis is a contraindication, to prevent device subsidence. ${ }^{13,16,18,19}$ The newer device is softer, absorbing $80 \%$ of its weight in water (instead of $60 \%$ previously), which may enable its use in flat endplates and moderate osteoporosis. Severe remodeling/irregularity is still a contraindication. Irregular/convex endplates were identified in $14.5 \%$ (17 out of 117 ) levels, using the 3 mid-sagittal $\mathrm{T}_{1^{-}}$ weighted sections on MRI.

Annular integrity was objectively evaluated on axial CTdiscogram sections, classifying tears as focal, partial, or global. ${ }^{24} \mathrm{~A}$ pitfall in using the nuclear replacement device in patients with herniated nucleus pulposus is that the degree of annular insufficiency cannot be determined on the MRI. ${ }^{25}$ If nucleus material can herniate, a complete tear through the fibers of the annulus must be present. This study did not include patients with disc herniations and clinical radiculopathy for this reason. Significant annular insufficiency was noted in $43.6 \%$ (51 of 117) of the levels, most frequently at L5-S1 where $61.8 \%$ (34 of 55) were insufficient in the presented series. The compressive and shear stresses are largest at L5-S1, which may explain the higher prevalence of annular insufficiency. The use of CT-discography is an attractive technique to objectively quantify annular integrity prior to prosthetic nucleus implantation; its use, however, has not been validated in clinical studies.

The impact of clinical parameters on patient management was highlighted, as an exclusion criteria of BMI $>30$ reduced the percentage of cases amenable to treatment with the device by $10.25 \%$ after exclusion of all radiographic contraindications and by $17.9 \%$ overall. The higher body weight of these patients may increase the stresses on the implant and thus facilitate herniations, making a BMI $>30$ an important contraindication to nuclear replacement. ${ }^{13,19}$ 
Reviewing the results in the present study, a useful workup for evaluating DDD patients as potential candidates for prosthetic disc nucleus should start with the clinical data. Cases with BMI $>30$ and severe osteoporosis should be excluded. These factors, however, can be favorably modified by weight reduction and appropriate medications. Attention should then be directed to radiographic contraindications: Schmorl's nodes, cases with disc collapse $>50 \%(<5 \mathrm{~mm}$ is probably not sensitive enough, and judging the degeneration of the adjacent level is also important), and irregular endplate shape on plain radiographs and MR scans should be excluded. Finally, annular deficiency on CT-discography can be objectively recorded and quantified.

Using these criteria, $50.4 \%$ of 117 levels had no radiographic contraindications to nuclear replacement. However, the most commonly affected level (L5-S1) could receive a nucleus device in only $25.5 \%$ of the cases, in contrast to the higher lumbar levels (L3-4 and L4-5) which had no radiographic contraindications in about $70 \%$ of the cases. A BMI $>30$ exclusion criteria reduced the rate of levels suitable for nuclear replacement to $40.2 \%$. L3-4 and L4-5 were again suitable for the device in a higher percentage of cases (50-59.1\%), whereas this was the case for only $21.8 \%$ of the L5-S1 levels. Based on patients and not levels, prosthetic disc nucleus was a treatment option for $28.3 \%$ of the patients (15 of 53) with 1-level disease, and for $34.5 \%$ of the patients (11 of 32) with 2-level disease. However, an additional $18.8 \%$ (6) of the latter patients could benefit from nuclear replacement at 1 level. At this time point the literature does not support use of prosthetic disc nucleus in 2 levels. We anticipate that similar to TDR, where increasing surgeon confidence and experience has enabled the application of this procedure to 2 levels, nuclear replacement may be used in patients with 2-level disease as well in the future.

This manuscript was submitted October 3, 2007, and accepted for publication February 5, 2008.

\section{REFERENCES}

1. Frymoyer JW Cats-Baril WL. An overview of the incidences and costs of low back pain. Orthop Clin North Am. 1991;22(2):263-271.

2. Grabois M. Management of chronic low back pain. Am J Phys Med Rehabil. 2005;84(3 Suppl):S29-41.

3. Cohen SP, Williams S, Kurihara C, Griffith S, Larkin TM. Nucleoplasty with or without intradiscal electrothermal therapy (IDET) as a treatment for lumbar herniated disc. J Spinal Disord Tech. 2005;18 SupplS119-124.

4. Errico TJ, Fardon DF, Lowell TD. Open discectomy as treatment for herniated nucleus pulposus of the lumbar spine. Spine J. 2003;3(3 Suppl):45S-49S.

5. Asazuma T, Masuoka K, Motosuneya T, Tsuji T, Yasuoka H, Fujikawa K. Posterior lumbar interbody fusion using dense hydroxyapatite blocks and autogenous iliac bone: clinical and radiographic examinations. J Spinal Disord Tech. 2005;18 Supp1S41-47.

6. Burkus JK, Schuler TC, Gornet MF, Zdeblick TA. Anterior lumbar interbody fusion for the management of chronic lower back pain: current strategies and concepts. Orthop Clin North Am. 2004;35(1):25-32.
7. Christensen FB. Lumbar spinal fusion. Outcome in relation to surgical methods, choice of implant and postoperative rehabilitation. Acta Orthop Scand Suppl. 2004;75(313):2-43.

8. Urban JP Roberts S. Degeneration of the intervertebral disc. Arthritis Res Ther. 2003;5(3):120-130.

9. Hilibrand AS Robbins M. Adjacent segment degeneration and adjacent segment disease: the consequences of spinal fusion? Spine J. 2004;4(6 Suppl):190S-194S.

10. Huang RC, Lim MR, Girardi FP, Cammisa FP, Jr. The prevalence of contraindications to total disc replacement in a cohort of lumbar surgical patients. Spine. 2004;29(22):2538-2541.

11. Gamradt SC Wang JC. Lumbar disc arthroplasty. Spine J. 2005;5(1):95103.

12. Guyer RD, McAfee PC, Hochschuler SH, Blumenthal SL, Fedder IL, Ohnmeiss DD, Cunningham BW. Prospective randomized study of the Charite artificial disc: data from two investigational centers. Spine J. 2004;4(6 Suppl):252S-259S.

13. Ray CD. The PDN prosthetic disc-nucleus device. Eur Spine J. 2002;11 Suppl 2S137-142.

14. Goins ML, Wimberley DW, Yuan PS, Fitzhenry LN, Vaccaro AR. Nucleus pulposus replacement: an emerging technology. Spine J. 2005;5317S5324S.

15. Cunningham ME, Girardi FP, Bertagnoli R: Nucleus ArthroplastyTM Technologies. Edited by Davis, RJ, and Girardi, FP, SAS 7 meeting, Berlin, Germany, Raymedica, LLC, 2007.

16. Bertagnoli R, Schonmayr R. Surgical and clinical results with the PDN prosthetic disc-nucleus device. Eur Spine J. 2002;11 Suppl 2S143-148.

17. Husson JL, Korge A, Polard JL, Nydegger T, Kneubuhler S, Mayer HM. A memory coiling spiral as nucleus pulposus prosthesis: concept, specifications, bench testing, and first clinical results. J Spinal Disord Tech. 2003;16(4):405-411.

18. Jin D, Qu D, Zhao L, Chen J, Jiang J. Prosthetic disc nucleus (PDN) replacement for lumbar disc herniation: preliminary report with six months' follow-up. J Spinal Disord Tech. 2003;16(4):331-337.

19. Klara PM Ray CD. Artificial nucleus replacement: clinical experience. Spine. 2002;27(12):1374-1377.

20. Shim CS, Lee SH, Park CW, Choi WC, Choi G, Choi WG, Lim SR, Lee HY. Partial disc replacement with the PDN prosthetic disc nucleus device: early clinical results. J Spinal Disord Tech. 2003;16(4):324-330.

21. Carragee EJ Alamin TF. Discography. a review. Spine J. 2001;1(5):36472.

22. Miyakoshi N, Abe E, Shimada Y, Hongo M, Chiba M, Sato K. Anterior decompression with single segmental spinal interbody fusion for lumbar burst fracture. Spine. 1999;24(1):67-73.

23. Pfirrmann CW, Metzdorf A, Zanetti M, Hodler J, Boos N. Magnetic resonance classification of lumbar intervertebral disc degeneration. Spine. 2001;26(17):1873-1878.

24. Sachs BL, Vanharanta H, Spivey MA, Guyer RD, Videman T, Rashbaum RF, Johnson RG, Hochschuler SH, Mooney V. Dallas discogram description. Anew classification of $\mathrm{CT} /$ discography in low-back disorders. Spine. 1987;12(3):287-294.

25. Collins CD, Stack JP, O'Connell DJ, Walsh M, McManus FP, Redmond $\mathrm{OM}$, Ennis JT. The role of discography in lumbar disc disease: a comparative study of magnetic resonance imaging and discography. Clin Radiol. 1990;42(4):252-257. 